J. Dairy Sci. 97:4658-4658

http://dx.doi.org/10.3168/jds.2014-97-7-4658

(C) American Dairy Science Association ${ }^{\circledR}, 2014$.

\title{
Erratum to "The dual effects of Maillard reaction and enzymatic hydrolysis on the antioxidant activity of milk proteins" (J. Dairy Sci. 96:4899-4911)
}

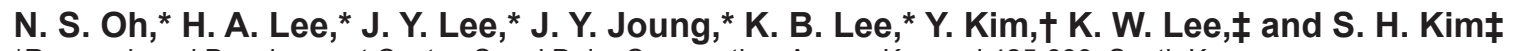

${ }^{*}$ Research and Development Center, Seoul Dairy Cooperative, Ansan, Kyunggi 425-839, South Korea

†Department of Animal Science and Institute of Rare Earth for Biological Application, Chonbuk National University, Jeonju, 561-756, South Korea

‡Division of Food Bioscience and Technology, College of Life Science and Biotechnology, Korea University, Seoul 136-701, South Korea

At the time of this study, author N. S. Oh was also affiliated with the Division of Food Bioscience and Technology, College of Life Science and Biotechnology, Korea University, Seoul 136-701, South Korea (footnote $\ddagger)$.

The authors regret the error.

\section{REFERENCES}

Oh, N. S., H. A. Lee, J. Y. Lee, J. Y. Joung, K. B. Lee, Y. Kim, K. W Lee, and S. H. Kim. 2013. The dual effects of Maillard reaction and enzymatic hydrolysis on the antioxidant activity of milk proteins. J. Dairy Sci. 96(8):4899-4911. 